\title{
Does Public Spending Structure Affect the Efficiency of Spending? Evidence from a Panel Tobit Model for Chinese Provinces
}

\author{
Zhirong $\mathrm{Ou}^{1}$ \\ Fuwen Zeng ${ }^{2}$ \\ *Xinyu Zhan" \\ '(Girldifi Iniversity, (iarlifif,, IK

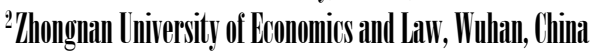

\begin{abstract}
The general financial stress confronting Chinese local governments requires public spending to become more efficient. While previous work has attempted to study what determines the efficiency, the focus was put on various factors that were not under direct control by policymakers. This paper revisits the issue, controlling the factors commonly found to be significant in the literature, by evaluating the role of the spending structure which can be easily adjusted by policymakers. The paper focuses on the investment ratio, as public investment is known to be a key driver of the Chinese economy. Using data of 31 provinces between 2000 and 2017, we estimated a Tobit model, with the efficiency of public spending calculated by data envelopment analysis (DEA). The efficiency of public spending is partially determined by the structure of the spending; the former is an increasing function of the latter up to an optimal rate, which is estimated to be between 19-23 percent. As most local governments are over-investing according to this standard, future improvement of budget management would require policymakers to concentrate much more on non-investment projects, such as spending on benefits, education and healthcare - hence, the provision of public goods and services.

Keywords: Efficiency, public spending, data envelopment analysis (DEA), panel Tobit model, China

JEL: D61, H11
\end{abstract}

In recent years, China has experienced a rapid fiscal expansion as its growth strategy changed from "speed-driven" to "quality-driven". The total national public spending has risen by about twenty times between 2000 and 2017, from 1.58 trillion Yuan to 20.3 trillion, implying an average growth of 16.3 percent per annum (The National Bureau of Statistics of China, 2019). However, the rise in fiscal revenue was not fast. Since 2008, a primary deficit has emerged; and the rising figure reflected the general, exacerbating financial stress confronting the local governments. On the one hand, the tax sharing reform greatly reduced local revenues, while burdens on local budgets remained ${ }^{1}$; on the other hand, tasks of promoting growth and urbanization - which also led to "fiscal competition" among local governments - became more onerous, which worsened the government's budget position. Despite the rising deficit, the return on public provision has not been as high. While public spending can be broadly categorized into three types - investment, goods consumption, and purchase of 
services, it is generally aware that none of these areas developed substantially compared to the input. The problem points directly to the efficiency of the spending, which is the focus of this research.

This paper studies how the structure of public spending affects the efficiency of it. It asks two specific questions: a) Whether the structure of spending affects its efficiency? b) Whether local government budgets are ill-structured? It focuses on the ratio of public investment to the whole public spending, for that public investment is known to be the most important fiscal instrument dominated the growth of the Chinese economy over the past twenty years. Since neither goods consumption nor purchases of service is productive, spending on these two categories can be defined more broadly to be "public consumption", whose ratio is simply one minus the investment ratio. This simplification allows us to focus just on the investment ratio.

Compared to previous works, this study is innovative in the way that it considers the structure of public spending, which is a factor that can be readily reviewed and revised by policymakers. While many scholars have studied what determined the efficiency of fiscal and/or monetary policy (Chen and Zhang, 2008; Chen and Zhang, 2011; Tang and Wang, 2012), Mandl, Dierx and Ilzkovitz (2008) pointed that previous works had mainly focused on factors that were practically "uncontrollable", as they were usually outcomes of policies (thus, endogenous, such as GDP growth and fiscal revenue), or factors rooted in the deep structure of the economy (which hardly shifted with policies, such as population density and openness of the economy). By contrast, the structure of spending is a factor policymakers have full and direct control, and is therefore more relevant from the decision-making viewpoint. Indeed, given that the debt issue of local governments is looming and that over-investment in some places has started to cause problems, it is worth considering how limited fiscal revenue may be allocated for it to be spent in the most efficient way.

This paper adopts a two-step approach. It first calculates the efficiency of public spending using data envelopment analysis (DEA). It then estimates a panel Tobit model allowing for selected control variables widely found to be significant, to examine the role of the investment ratio. The efficiency of public spending is found to be an increasing function of the investment ratio up to an optimal rate. Compared to the optimal rate, the data show that most local governments have been over-investing. A more efficient allocation of future revenue would require spending to lean more on non-investment items, hence, more on the provision of public goods and services.

The rest of this paper is organized as follows: Section 2 reviews the literature; Section 3 describes the methodology; Section 4 reports the results; Section 5 concludes the paper; Section 6 discusses the policy implications; Section 7 reflects the limitations and directions for future studies. 


\section{Ou et al.}

\section{LITERATURE REVIEW}

Existing studies on the efficiency of public spending have mainly been comparative research, focusing on how environment and/or institutional settings could have resulted in differences in the efficiency of parts, or the whole schedule, of the government budget. Gerdtham et al. (1995) studied the healthcare system of the member countries of the Organization for Economic Co-operation and Development (OECD). They found that reimbursements to privately-managed systems were more efficient than direct spending on publicly-managed systems. Gupta and Verhoeven (2001) considered the education and health spending in Africa, Asia, and Western Hemisphere, and found high government wages and intra-sectoral allocation of government resources explained why efficiency was low in these areas. Afonso, Schuknecht and Tanzi (2005) constructed a pooling of US and OECD countries and found that the inefficiency of public spending was partially due to government size. Afonso and Aubyn (2006) investigated the education sector; they found that the efficiency of educational spending was affected not only by economic development, but also by educational attainment. Borger and Kerstens (1996) studied the Belgian data and found that besides educational attainment, higher population density which implied a lower average cost of management - improved efficiency, whereas higher tax revenue undermined efficiency due to wastes. Similarly, Hauner (2008) studied the Russian data and found that the larger the scale of government spending, the lower the efficiency of the spending.

Literature shows that similar type of studies exploring efficiency of the spending has been conducted in China. Chen and Zhang (2008) compared the episodes before and after the tax sharing reform and found that the reform clearly improved the overall efficiency. Tang and Wang (2012) compared different geographical regions; they found that the Mid-China, whose level of economic development was below the East but above the West, performed the best on efficiency. Liu and Liu (2016) studied the health sector. They found that, although health spending became more and more efficient for the sector as a whole, the efficiency of personal spending was declining. Zhang et al. (2019) studied the spending on environmental protection; they found that efficiency rose with foreign direct investments but fell with fiscal decentralization.

Unfortunately, although the above studies have covered quite varied aspects of the efficiency of public spending, none of them was able to evaluate the structure of the spending itself. As Li (2009) has pointed, among all potential factors that could have affected efficiency, the structure of spending would be a fundamental one, as it determined the fund's allocation in the first place. The idea may be illustrated using a simple model where the government chooses between public investment and other spending in an efficiency maximization problem. Let the government, as illustrated in Figure 1, be an efficiency maximiser who allocates fiscal income in each period between public investment and other 
spending. The government faces a map of efficiency frontiers denoted by $e_{1}, e_{2}$ and $e_{3}$, where the further the frontier is from the origin, the higher the efficiency the government enjoys. For given fiscal income $A B$, both $P_{1}$ and $P_{2}$ are sub-optimal spending structures, as the former represents underinvestment, while the latter represents over-investment. The optimal combination of investment and other spending is represented by the $\left(\mathrm{P}_{\mathrm{a}}, \mathrm{P}_{\mathrm{b}}\right)$ pair where the efficiency frontier $e_{2}$ is tangent with $A B$ at $P^{*}$. Thus, at least theoretically, there exists an optimal investment ratio at which the efficiency of public spending can be maximized.

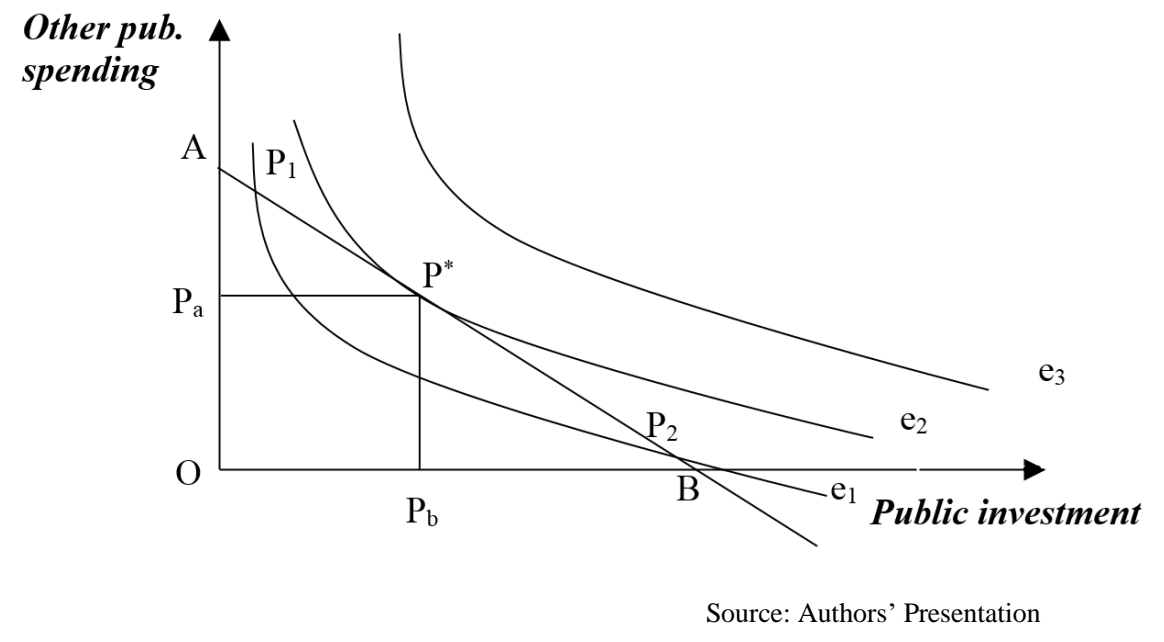

Figure 1. Structure of Public Spending and Efficiency

The existence of such optimal ratio is precisely what we aim to test and evaluate in the following work. Specifically, we set up the following hypotheses:

$H_{1}$ : The structure of public spending affects the efficiency of the spending in a non-linear manner.

$\mathrm{H}_{2}$ : The structure of public spending affects the efficiency of the spending in a non-linear manner and the marginal impact is partially affected by economic growth.

\section{METHODOLOGY}

\section{Data}

The data we use were annual data of 31 Chinese provinces between 2000 and 2017. Except for the efficiency data, the time series were collected from the China Statistics Year Book, China Labor Year 


\section{Ou et al.}

Book, and the Statistics Year Books for each province via the CNKI database (China National Knowledge Infrastructure, 2019). While descriptive statistics of the data are reported following the description of the model, in the next two subsections we explain our measurement of the structure and efficiency of public spending.

\section{-The Structure of Public Spending}

The structure of public spending is defined as the ratios of different spending to total spending in a fiscal year. Following Aschauer (1989), we categorized the spending into two types - one directly related to production which we call "public investment", the other covering spending on public goods and services which we call "public consumption". The former can be, for example, public investment in infrastructure, exploitation of natural resources, and transfers to state-owned enterprises. The latter includes expenditure on education, health, social security, and public services.

Figure 2 plots the public investment ratios for the main regions of China between 2000 and 2017 . The East, the Middle and the West are similar in pattern, and they all had high investment ratios. At the country level the ratio was about 33 percent, which was three times that in the US and six times that in the Euro area ${ }^{2}$. The ratio had a modest tendency of falling before 2007. This was mainly due to the

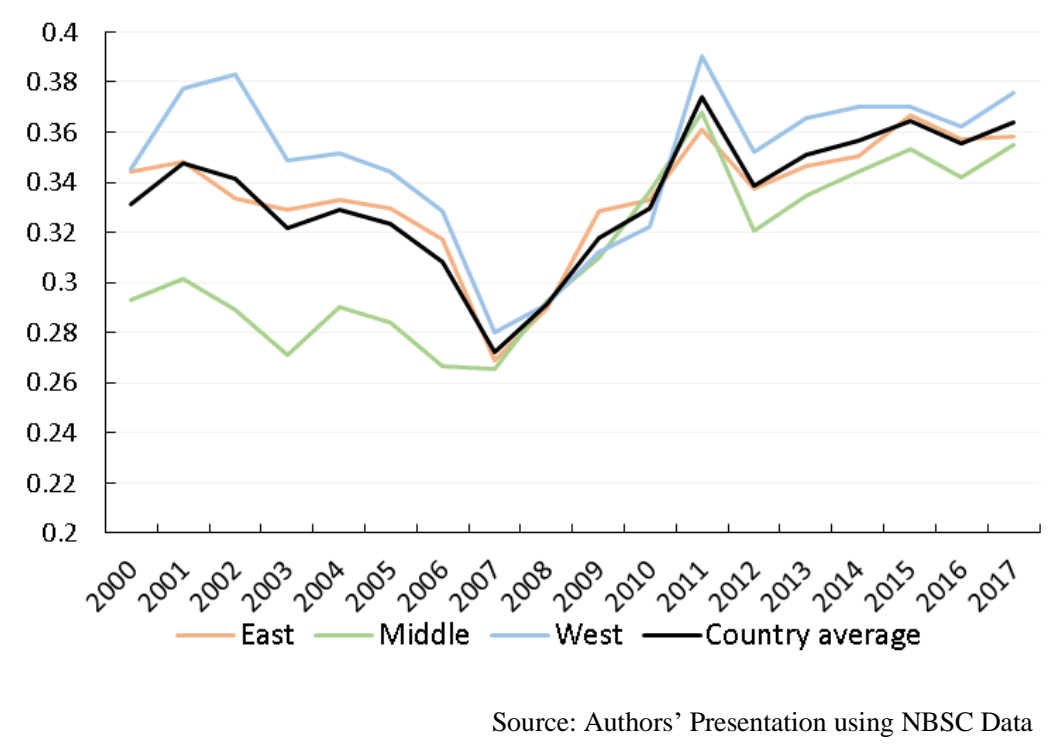

Figure 2. Public Investment in China as a Ratio to Total Spending

overheated Chinese economy at the start of the 2000s, which made the fiscal authority more prudential in implementing new investment projects. Behind this prudence it was the tension between the declined food supply and the excess rise in fixed capital in the other sectors at the time. The ratio 
reached the minimum in 2007, and then reversed, as the global financial crisis forced the Chinese government to implement a series of fiscal stimulus packages dominated by public investments. The ratio reached the peak in 2011 exceeding 37 percent. It then leveled off at just about the same ratio.

At the regional level, both the Middle and the West are outliers before 2007: The Middle clearly uninvested, while the West clearly overinvested, compared to the East and the national average. The former reflects that fiscal expansion at the time was biased towards the East and the West, which left the Middle behind. The East, being the most developed region, was always favored by capital. The West, being the least developed, nevertheless received particularly more support from the central government which aimed for a balanced growth. The several government-led initiatives, such as the Western Development Initiative, then made the West the most invested region (in terms of the investment ratio). However, all this divergence was substantially reduced since the financial crisis after which the fiscal authority had to reallocate the resources.

We omitted to plot the public consumption ratios to keep the figure concise. By definition, the timelines of them would just mirror the investment ratios.

\section{-The Efficiency of Public Spending}

The efficiency of public spending is defined as the ratio of actual outputs to the "potential" outputs, given inputs related to public spending. The efficiency is calculated by data envelopment analysis (DEA) allowing for variable returns to scale (Banker, Charnes and Cooper,1984). We considered only one input here, which is the total public spending per capita. Outputs were chosen to cover a range of economic and social indicators that fiscal policy in China is known to aim; the former consisted of GDP per capita, and disposable income per capita in both urban and rural areas, whereas the latter covered developments in education, health care and infrastructure, which are detailed in Table 1 (see Appendix-I). The efficiency of an individual decision-making unit (DMU) was evaluated by comparing the position of an overall output indicator for that unit, to the frontier formed by the same indicator for all units. The index is a number between zero and one ${ }^{3}$.

Figure 3 plots the calculated efficiency. The East and the Middle were always more efficient. The former was led by the latter in the early 2000s, but it caught up finally; and the two regions converged after the crisis. The West was clearly less efficient, but its pattern mimicked that of the Middle. The country-level score varies between $0.6-0.7$, showing public spending was, overall, reasonably efficient.

\section{Empirical Model}

In this section we set up the benchmark empirical model, allowing for control factors commonly found 


\section{Ou et al.}

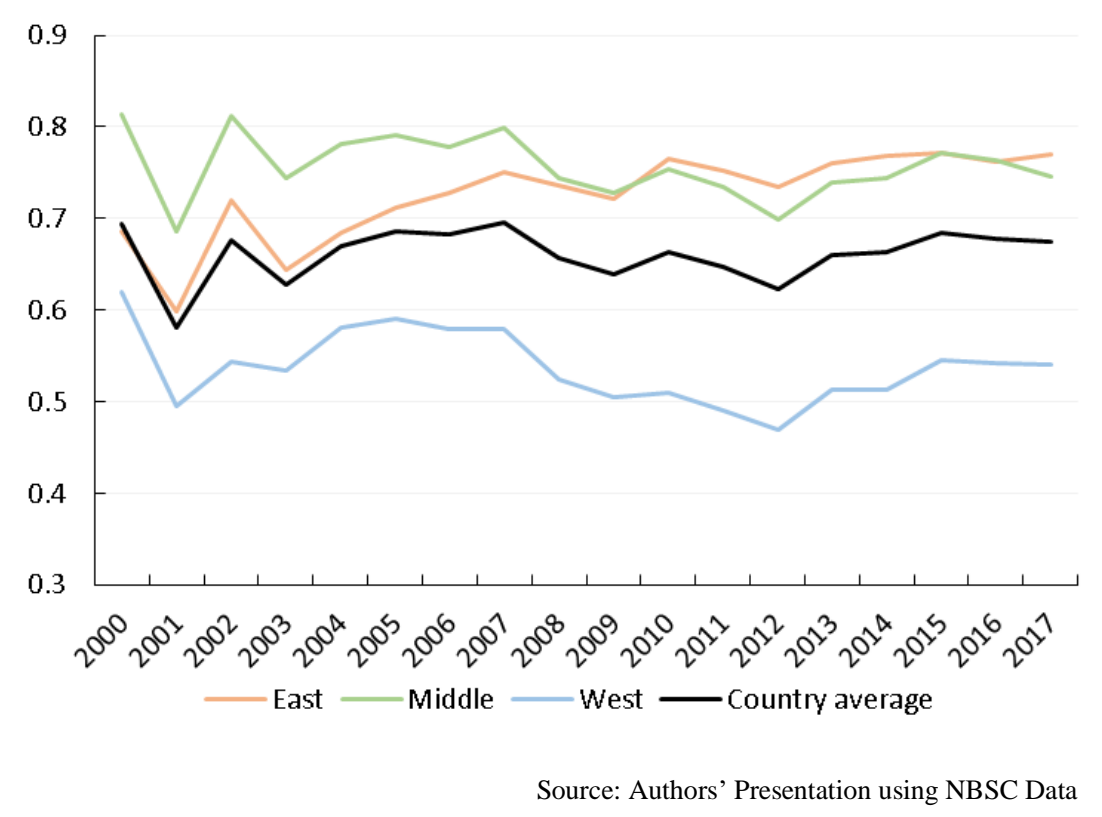

Figure 3. Efficiency of Public Spending Calculated by DEA

to be significant as reviewed earlier, for $H_{1}$ to be tested. Specifically, we modeled the relationship between the efficiency of public spending $(E f f)$ and the ratio of public investment $(P / n v)$ in a panel Tobit model setting. The Tobit model features a "censored" dependent variable, whose value is set to the boundary value allowed by the theory when the actual observed value is beyond that theoretical boundary. Using the OLS method with censored data will cause the least squares estimates to be biased and inconsistent. Since the efficiency scores calculated by DEA are, by definition, "censored from above" (i.e., $E f f_{i t}=\operatorname{Min}\left(E f f_{i t}^{D E A}, 1\right)$ ), the OLS estimator was no longer appropriate. For this reason, a Tobit model was used instead.

We define:

$$
E f f_{i t}=\left\{\begin{array}{r}
\alpha+\beta \cdot P \operatorname{Inv} v_{i t}+\gamma \cdot P \operatorname{Inv} v_{i t}^{2}+X_{i t} \phi+\delta_{i}+\tau_{t}+\varepsilon_{i t}, \text { if } 0<E f f_{i t}<1 \\
1, \text { if } \quad \text { Eff } f_{i t}=1
\end{array}\right.
$$

where $\alpha$ is the constant, $X=\left\{X_{i t}^{1}, \ldots, X_{i t}^{K}\right\}$ is a vector of control variables, $\phi$ is a $K X 1$ vector of coefficients, $\delta_{i}$ is the unit-specific effect, $\tau_{t}$ is the time fixed effect, and $\varepsilon_{i t} \sim N\left(0, \sigma^{2}\right)$ is the random error for each cross-sectional unit. When $E f f_{i t}=1$, (1) reduces to $E f f_{i t}=1$; data from this observation will not be used for estimation. When $0<E f f_{i t}<1$, Eff $_{i t}=\alpha+\beta \cdot P \operatorname{Inv}_{i t}+\gamma \cdot P \operatorname{Inv} v_{i t}^{2}+X_{i t} \phi+\delta_{i}+\tau_{t}+\varepsilon_{i t}$, data from this observation will be used 
for estimation. By definition, Eff should never be below zero. Hence, estimation of equation (1), the Tobit model, is essentially an estimation combined with an observation selecting process confined by the measurement of the dependent variable.

A key assumption regarding the specification of equation (1) is that, by allowing for a squared term $\left(P / n V^{2}\right)$, it assumes there exists an "optimal" investment ratio which maximizes the efficiency, ceteris paribus. This makes sense in practice if one considers diminishing return; while rising investment may always imply rising output, its marginal impact is not likely. Numerically, this would imply $\gamma<0$, and that the marginal impact of PInv on Eff to depend on the actual ratio of public investment. Since, Plnv $E$ $[0,1]$, for $\frac{\partial E f f}{\partial P I n v}$ to be not always negative, it also requires $\beta>0$.

The control variables were chosen to be human capital $(H C)$, population density $(P O P)$, openness (Open), growth rates of GDP per capita (GGDP), government size (GovSize) and fiscal revenue per capita (GRev). These are variables broadly found to be significant in explaining the efficiency in previous works (e.g., Chen and Zhang, 2008; Chen and Zhang, 2011; Tang and Wang, 2012).

The model was estimated by using Stata 14, with annual data of 31 provinces between 2000 and 2017. The measurement and descriptive statistics are detailed in Table 2.

\begin{tabular}{cccccc}
\hline Variables & Definition & Mean & S.D. & Min & Max \\
\hline PInv & Ratio of pub. inv. to tot. pub. spd. & 0.3343 & 0.0531 & 0.1897 & 0.5039 \\
HC & Average years of education & 7.9698 & 1.2845 & 3.0000 & 12.3700 \\
Pop & Number of people per km ${ }^{2}$ & 0.4159 & 0.6066 & 0.0021 & 3.8381 \\
Open & Ratio of import and export to GDP & 0.3107 & 0.3833 & 0.0170 & 1.7222 \\
GGDP & Per capita GDP growth rate & 3.0569 & 2.4118 & 0.2759 & 12.8994 \\
GovSize & Gov. consumption to GDP & 0.1562 & 0.0607 & 0.0845 & 0.5226 \\
GRev & Per capita general budget income & 0.3329 & 0.3896 & 0.0209 & 2.7470 \\
\hline
\end{tabular}

Source: Authors' Computation using Stata 14

Table 2. Measurement of Data and Descriptive Statistics

\section{RESULTS}

\section{The Correlation Matrix}

We start by reporting the correlation matrix for all the variables as shown in Table 3. The first column shows the correlations between efficiency and the other variables. The correlation coefficient between 


\section{Ou et al.}

efficiency and public investment is -0.63 which is reasonably high. This supports the inclusion of the investment ratio in our benchmark regression ${ }^{4}$. The table also reports the correlation coefficients between the exogenous variables. Most values are reasonably low, though some correlations among the control values are higher. Nevertheless, since these correlations do not affect either the theoretical interpretation or the empirical estimate of the marginal impact of Plnv on Eff (which is the focal point of this paper), they do not affect our study. The only correlation that might be a concern is the one between Plnv and GovSize (0.80), which is relatively high. In order to check how this correlation might affect our finding, we conduct a robustness check by dropping GovSize for a new estimation. We report the finding in Table 6 (see Appendix-II). We found that the inclusion/removal of GovSize hardly affects the estimates of our models.

\begin{tabular}{c|cccccccc}
\hline \multicolumn{2}{c}{ Eff } & PInv & HC & Pop & Open & GGDP & GovSize & GRev \\
\hline Eff & 1.0000 & & & & & & \\
PInv & -0.6339 & 1.0000 & & & & & \\
HC & 0.1647 & -0.4230 & 1.0000 & & & & \\
Pop & 0.0223 & -0.2076 & 0.4840 & 1.0000 & & & & \\
Open & -0.0290 & -0.2188 & 0.4498 & 0.7087 & 1.0000 & & \\
GGDP & 0.0224 & -0.0259 & 0.7471 & 0.5288 & 0.4711 & 1.0000 & & \\
GovSize & -0.6264 & 0.8050 & -0.4153 & -0.1984 & -0.1148 & -0.1357 & 1.0000 & \\
GRev & -0.1020 & 0.0238 & 0.7065 & 0.6465 & 0.5231 & 0.9297 & -0.0310 & 1.0000 \\
\hline
\end{tabular}

Source: Authors' Computation using Stata 14

Table 3. The Correlation Matrix

\section{-Does Public Spending Structure Affect the Efficiency of Spending?}

Table 4 reports the Maximum Likelihood (ML) estimates of the model. All the control variables, except $H C$ and GovSize, are highly significant. Of these, Pop affects efficiency positively, while Open, GGDP and GRev affect efficiency negatively. The estimated coefficients of our most interested variables, P/nv and $P / n v^{2}$, are 0.82 and -1.77 , respectively, with the expected signs. The estimates are significant not only individually but also jointly ${ }^{5}$.

The above suggests the structure of public spending does affect the efficiency of spending. According to the estimation, a 1 percent rise in the investment ratio would change the efficiency by 
$\frac{\partial E f f}{\partial P I n v}=0.82+2 \times(-1.77) \times P / n v$ percent - hence, a positive marginal impact when P/nv is below 23 percent and a negative impact when it exceeds the threshold. Since $\frac{\partial E f f}{\partial P \operatorname{In} v \cdot \partial P \operatorname{In} v}=2 \gamma<0$, it also confirms our hypothesis $\left(\mathrm{H}_{1}\right)$ of concavity of the efficiency function with respect to Plnv. Hence, overinvesting can impair efficiency.

\begin{tabular}{|c|c|c|c|c|c|c|c|}
\hline PInv & $P I n v^{2}$ & $\overline{H C}$ & Pop & Open & GGDP & GovSize & GRev \\
\hline $0.8225^{*}$ & $-1.7711^{* *}$ & 0.0056 & $0.1750^{* *}$ & $-0.0956^{* *}$ & $-0.1882^{* *}$ & -0.0918 & $-0.1017^{* *}$ \\
\hline$(0.4440)$ & $(0.6277)$ & $(0.0093)$ & $(0.0242)$ & $(0.0217)$ & $(0.0617)$ & $(0.0857)$ & $(0.0304)$ \\
\hline \multicolumn{4}{|c|}{ Joint significance of PInv \& PInv ${ }^{2}(f$-stat $)$} & \multicolumn{4}{|c|}{33.83} \\
\hline \multicolumn{4}{|c|}{ Unit-specific effect } & \multicolumn{4}{|c|}{ Yes } \\
\hline \multicolumn{4}{|c|}{ Time fixed effect } & \multicolumn{4}{|c|}{ Yes } \\
\hline \multicolumn{4}{|c|}{ Number of Obs } & \multicolumn{4}{|c|}{527} \\
\hline
\end{tabular}

Source: Authors' Computation using Stata 14

Note: $* *$, and $*$ denote the level of significance at $1 \%$, and $5 \%$, respectively.

Table 4. ML Estimates of the Benchmark Model

\section{-Have Local Governments Overinvested?}

Figures 4-6 (shown below) compare the timelines of public investment ratio of local governments in the East, the Middle, and the West, to the optimal investment ratio found in the previous section. It turns out that all provinces have over-invested by a substantial margin - about 50 percent - compared

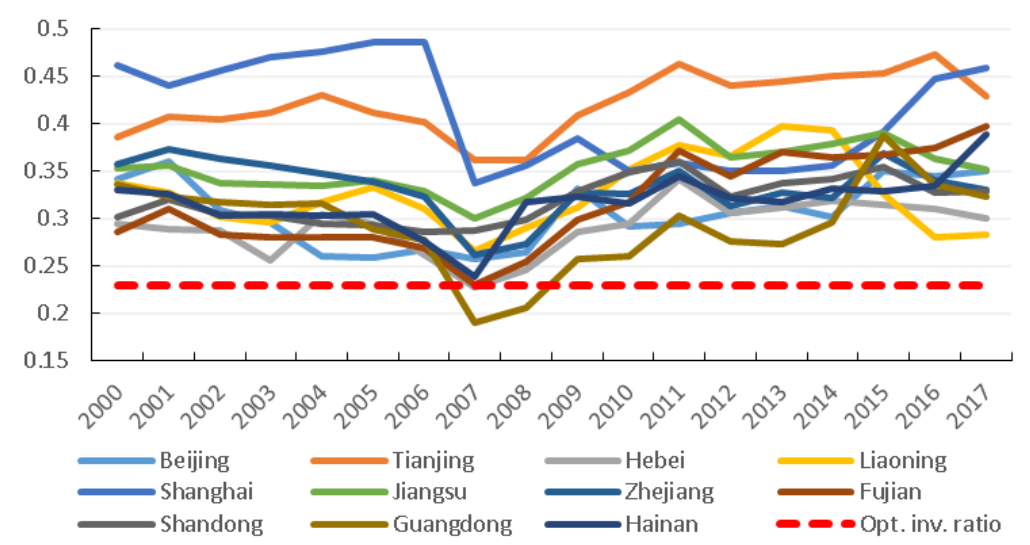

Source: Authors' Presentation using NBSC Data

Figure 4. Public Investment Ratio in East Provinces 


\section{Ou et al.}

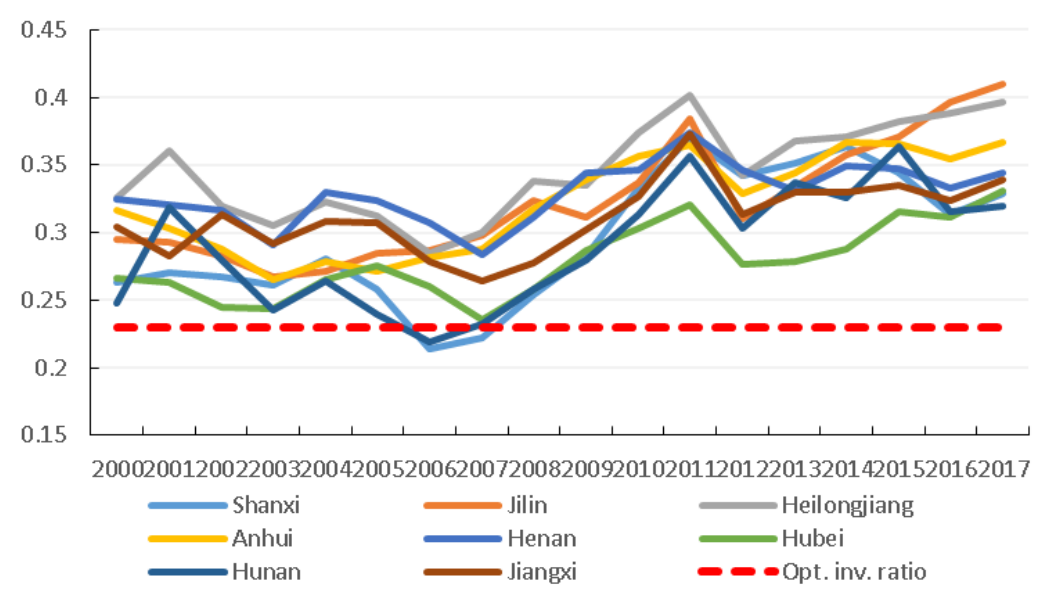

Source: Authors' Presentation using NBSC Data

Figure 5. Public Investment Ratio in Middle Provinces

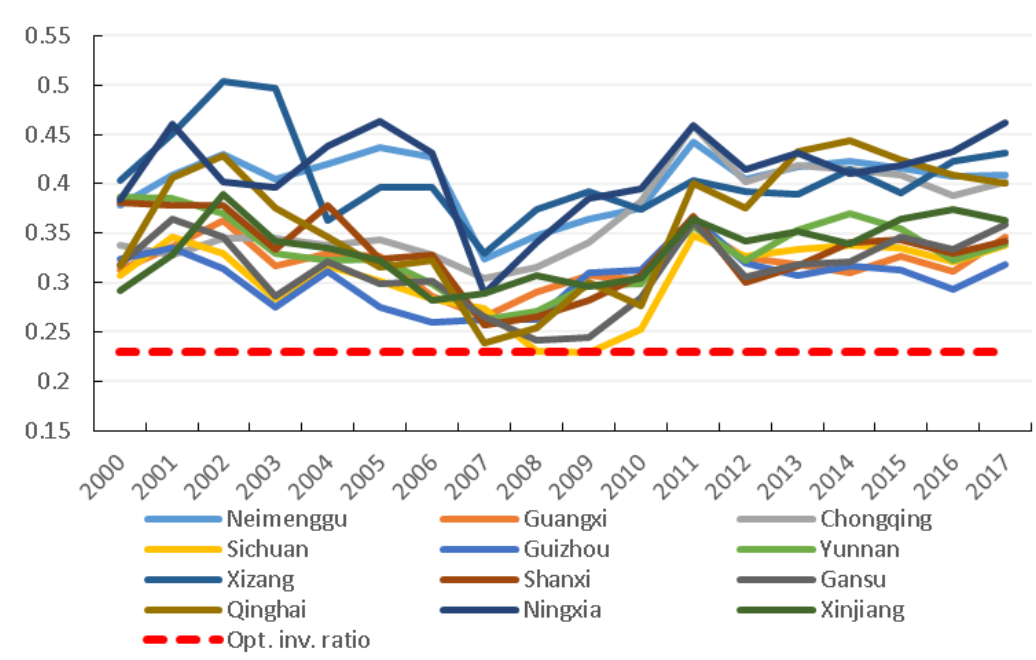

Source: Authors' Presentation using NBSC Data

Figure 6. Public Investment Ratio in West Provinces

to the optimal rate. The bias was about the same across the whole country, though it was more stable in the East and the West, while the middle provinces experienced increasing bias after the crisis. The most over-invested provinces in the East are Tianjin and Shanghai, whose average investment ratios both exceed 40 percent. The most over-invested middle provinces are Heilongjiang (35\%), Henan (33\%), Jilin (32\%), and Anhui (32\%). The most over-invested west provinces are Inner Mongolia, Tibet and Ningxia (all above 40\% throughout), and also Chongaing and Qinghai (around 43\% since 2011). 
Overall, we find that, apart from a couple of outliers (such as Guangdong in the East and Hebei in the Middle), local government budgets in China have suffered a severe efficiency problem due to overinvestments.

\section{-Accounting for Economic Growth? A Model Variant with Cross-term between GDP Growth and the Investment Ratio}

It may be argued that, although the benchmark model (1) has allowed for the role of GDP growth, the growth itself could have had an impact on how efficiency is affected by the other variables, especially the investment ratio which tends to reflect fiscal authorities' responses to local economic development. For example, raising the investment ratio in a well-developed region may result in "excess capacity" - a widely concerned efficiency problem confronting Chinese officials in recent years. On the contrary, where the local economy is underdeveloped, a modest rise in public investment (such as investing in infrastructure) may turn out to be very efficient due to fiscal multipliers.

In this section, we tested second hypothesis $\left(\mathrm{H}_{2}\right)$ by adding to the benchmark model a cross-term between GDP growth and the investment ratio:

$$
\begin{aligned}
& E f f_{i t} \\
& =\left\{\begin{aligned}
\alpha+\beta \cdot P I n v_{i t}+\gamma \cdot P \operatorname{Inv} v_{i t}^{2}+\theta \cdot G G D P_{i t} \cdot P I n v_{i t}+X_{i t} \phi+\delta_{i}+\tau_{t}+\varepsilon_{i t}, & \text { if } 0<E f f_{i t}<1 \\
1, & \text { if } \quad \text { Eff }_{i t}=1
\end{aligned}\right.
\end{aligned}
$$

where $\theta$ measures the impact of GDP growth on the marginal impact of the investment ratio on

\begin{tabular}{|c|c|c|c|c|c|c|c|c|}
\hline PInv & $\operatorname{PInv}^{2}$ & $G G D P \times P I n v$ & $H C$ & Pop & Open & GGDP & GovSize & GRev \\
\hline 0.1142 & $-1.3267^{*}$ & $3.1229^{* *}$ & 0.0052 & $0.1800^{* *}$ & $-0.1123^{* *}$ & $-1.2073^{* *}$ & -0.0720 & $-0.1257^{* *}$ \\
\hline$(0.4627)$ & $(0.6230)$ & $(0.6942)$ & $(0.0091)$ & $(0.0237)$ & $(0.0217)$ & $(0.2345)$ & $(0.0842)$ & $(0.0303)$ \\
\hline \multicolumn{5}{|c|}{ Joint significance of $P I n v, P I n v^{2} \& G G D P \times \operatorname{PInv}(f$-stat $)$} & \multicolumn{4}{|c|}{55.16} \\
\hline \multicolumn{5}{|c|}{ Unit-specific effect } & \multicolumn{4}{|c|}{ Yes } \\
\hline \multicolumn{5}{|c|}{ Time fixed effect } & \multicolumn{4}{|c|}{ Yes } \\
\hline \multicolumn{5}{|c|}{ Number of Obs. } & \multicolumn{4}{|c|}{527} \\
\hline
\end{tabular}
efficiency. The estimated model is reported in Table 5.

Source: Authors' Computation using Stata 14

Note: $* *$, and $*$ denote the level of significance at $1 \%$, and $5 \%$, respectively.

Table 5. ML Estimates of the Model Allowing for GGDP $\times$ PInv 


\section{Ou et al.}

It turns out that the cross-term is highly significant. Value of $\theta$ is positive (3.12), suggesting higher growth implies higher marginal efficiency of investing. This is broadly in line with the perception that faster growth generally happens in less developed areas with a higher marginal return. Now that $\frac{\partial E f f}{\partial P I n v}$ $=\beta+2 \gamma \cdot P / n v_{i t}+\theta \cdot G G D P_{i t}$, the optimal investment ratio becomes a function of growth. Using the sample mean of the growth rates, we found the "Iong-run'" optimal ratio reduced to 19 percent at the country level, and 18 percent, 19 percent, and 21 percent if we further narrow down the scope for the East, the Middle, and the West, respectively. Thus, a slightly lower optimal ratio compared to the implication of the benchmark model.

\section{CONCLUSION}

This paper studied how the structure of public spending affects the efficiency of spending in China. It focuses on the investment ratio, which is exceptionally high compared to the general practice in the rest of the world. By estimating a Tobit model allowing for a number of control variables, we find that the efficiency of public spending is an increasing function of the investment ratio up to an optimal rate. The estimated optimal rate is 23 percent (or 19\% if GDP growth is assumed to affect the marginal impact of the investment ratio). According to this standard, most local governments have failed to allocate their sources efficiently; public spending has leaned far too much on investment, which is inefficient, as policy target is multifaceted covering not only economic indicators but also social indicators.

\section{IMPLICATIONS}

The above findings provide valuable implications both for the theory and for policies. For the former, it testifies to the hypotheses that the structure of public spending itself matters for the efficiency of the spending and that, an optimal spending structure exists. For the latter, it implies that, given the financial stress confronting local budgets as reforms in China deepen, an "efficient" allocation of fiscal revenue would require policymakers to concentrate much more on non-productive projects, such as spending on social benefits, education, and healthcare - hence, the provision of public goods and services. Local governments have been clearly over-investing, which needs to be reduced for the overall budget efficiency to be improved. Future investment projects should be evaluated, monitored, and reviewed more carefully to avoid unnecessary and repeated investments.

\section{LIMITATIONS AND FUTURE DIRECTIONS}


The main limitation of this study lies in that, as a complete set of city-level data is not available, we could only construct our panel model at the provincial level. This may not fully reflect how "local" budgets are managed in practice, as most public spending issues in China happen at the city level. While our study - using data at a "higher" level - remains a good reflection of the reality, a fruitful direction for future research would be to carry out a robustness check with city-level data. Another interesting extension would be to shift the focus to "public consumption". In this paper we did not probe into the constituents of it. Nevertheless, within this broad category there are spending of quite different natures, which is worth investigating in the future. Both these extensions are on our research agenda.

\section{REFERENCES}

Afonso, A., Schuknecht, L. \& Tanzi, V. (2005). Public sector efficiency: An international comparison. Public Choice, 123(3): 321-347. https://doi.org/10.1007/s11127-005-7165-2

Afonso, A. \& Aubyn, M. (2006). Cross-country efficiency of secondary education provision: A semi-parametric analysis with non-discretionary inputs. Economic Modelling, 23(3): 476-491. https://doi.org/10.1016/j.econmod.2006.02.003

Aschauer, D. (1989). Is public expenditure productive? Journal of Monetary Economics, 23(2) :177-220 . https://doi.org/10.1016/0304-3932(89)90047-0

Banker, R. D., Charnes, A. \& Cooper, W. (1984). Some models for estimating technical and scale inefficiencies in data envelopment analysis. Management Science, 30(9): 1078-1092. https://doi.org/10.1287/mnsc.30.9.1078

Borger, B. D. \& Kerstens, K. (1996). Cost efficiency of Belgian local governments: A comparative analysis of FDH, DEA, and econometric approaches. Regional Science and Urban Economics, 26(2):145-170. https://doi.org/10.1016/01660462(95)02127-2

Chen, S. \& Zhang, J. (2008). Efficiency of local government financial expenditure in China: 1978-2005. Social Sciences in China, 4, 65-78.

Chen, Z. \& Zhang, Z. (2011). The influencing factors analysis of regional efficiency of public expenditure in China based on DEA-Tobit two-stage model. Journal of Nanjing University of Finance and Economics, 5, 42-50.

China National Knowledge Infrastructure (2019). Retrieved July 20, 2019, from https://oversea.cnki.net/index

Gerdtham, U., Jönsson, B., MacFarlan, M. \& Oxley, H. (1998). The determinants of health expenditure in the OECD countries: A pooled data analysis. In P. Zweifel (Eds), Health, the Medical Profession, and Regulation: 113-134. Boston: Springer.

Gupta, S. \& Verhoeven, M. (2001). The efficiency of government expenditure experiences from Africa. Journal of Policy Modelling, 23(4):433-467. https://doi.org/10.1016/S0161-8938(00)00036-3

Hauner, D. (2008). Explaining differences in public sector efficiency: Evidence from Russia's regions. World Development, 36(10): 1745-1765. https://doi.org/10.1016/j.worlddev.2007.09.011

Li, Y. (2009). Structural changes and efficiency of China's fiscal expenditures. China Economic Quarterly, 9(1): $307-332$. http://doi.org/10.13821/j.cnki.ceq.2010.01.013

Liu, D. \& Liu, Z. (2016). The evolution and influencing factors of Chinese out-of-pocket healthcare expenditure efficiency: DEA-Tobit analysis based on panel data. International Business and Management, 12(2): 10-17. http://dx.doi.org/10.3968/8271

Mandl, U., Dierx, A. \& Ilzkovitz, F. (2008). The effectiveness and efficiency of public spending. Working paper no.301, European Commission, Brussels, Belgium. http://dx.doi.org/10.2765/22776

Tang, Q. \& Wang, B. (2012). An empirical analysis of the efficiency and influencing factors of China's local government fiscal expenditure. Journal of Financial Research, 2, 48-60.

The National Bureau of Statistics of China (2019). Retrieved July 20, 2019, from http://www.stats.gov.cn/english/Statisticaldata/AnnualData/.

Zhang, J., Qu, Y., Zhang, Y., Li, X. \& Miao, X. (2019). Effects of FDI on the efficiency of government expenditure on environmental protection under fiscal decentralization: A spatial econometric analysis for China. International Journal of Environmental Research and Public Health, 16(14), 2496. https://dx.doi.org/10.3390\%2Fijerph16142496 


\section{Ou et al.}

\section{ENDNOTES}

${ }^{1}$ The Reform, took place in 1994, was aimed at improving the financial position of the Central government, by largely increasing its sharing of total tax revenue relative to that of the local governments.

${ }^{2}$ The ratios for US and EA over the same period were, respectively, about $11 \%$ and $6 \%$.

${ }^{3}$ The most efficient units have output indicators lying on the frontier and are scored 1; a completely inefficient unit produces no output and is scored 0 .

${ }^{4}$ Since our benchmark model assumes a non-linear relationship between Eff and Plnv, the sign of this correlation coefficient is not quite relevant here.

${ }^{5}$ To validate this benchmark finding, we considered four alternative specifications, one with the social factors ( $H C$ and $\left.P O P\right)$ excluded, one with the macroeconomic factors (Open and GGDP) excluded, one with the fiscal factors (GovSzie and GRev) excluded, and one with all the control factors excluded. The likelihood ratio test suggests that all these model variants are significantly "less likely" compared to Model (1). Hence, there is good evidence that this benchmark specification is favored by the data. A similar exercise is conducted for Model (2) which we consider below. We found similar result. The likelihood ratio tests for these alternative specifications are reported in Table 7 in Appendix-III. 


\begin{tabular}{|c|c|}
\hline Inputs & Outputs \\
\hline $\begin{array}{l}\text { Total public } \\
\text { spending per } \\
\text { capita }\end{array}$ & $\begin{array}{l}\text { GDP per capita } \\
\text { Disposable income per capita in urban areas } \\
\text { Disposable income per capita in rural areas } \\
\text { Ratio of faculty and staff in higher education institutions to total regional population } \\
\text { Ratio of faculty and staff in secondary vocational schools to total regional } \\
\text { population } \\
\text { Ratio of faculty and staff in general secondary schools to total regional population } \\
\text { Ratio of faculty and staff in primary schools to total regional population } \\
\text { Medical beds per capital } \\
\text { Doctors per capital } \\
\text { Ratio of Effective irrigated acreage to total crop acreage } \\
\text { Railway mileage per capita } \\
\text { Electricity consumption per capita in rural areas }\end{array}$ \\
\hline
\end{tabular}

Table 1. Factors Chosen to Calculate DEA Efficiency 
Ou et al.

Appendix-II

\begin{tabular}{|c|c|c|c|c|}
\hline & \multicolumn{2}{|c|}{ With GovSize } & \multicolumn{2}{|c|}{ Without GovSize } \\
\hline & Model (1) & Model (2) & Model (1) & Model (2) \\
\hline$P \operatorname{Inv}$ & $\begin{array}{c}0.8225^{*} \\
(0.4440)\end{array}$ & $\begin{array}{c}0.1142 \\
(0.4627)\end{array}$ & $\begin{array}{c}0.8004^{*} \\
(0.4436)\end{array}$ & $\begin{array}{c}0.0903 \\
(0.4619)\end{array}$ \\
\hline$P \operatorname{Inv} v^{2}$ & $\begin{array}{c}-1.7711^{\text {**** }} \\
(0.6277)\end{array}$ & $\begin{array}{c}-1.3267^{* *} \\
(0.6230)\end{array}$ & $\begin{array}{c}-1.7222^{* * *} \\
(0.6262)\end{array}$ & $\begin{array}{c}-1.2844^{* *} \\
(0.6210)\end{array}$ \\
\hline$G G D P \times P I n v$ & & $\begin{array}{c}3.1229^{* * *} \\
(0.6942)\end{array}$ & & $\begin{array}{c}3.1518^{* * *} \\
(0.6934)\end{array}$ \\
\hline$H C$ & $\begin{array}{c}0.0056 \\
(0.0093)\end{array}$ & $\begin{array}{c}0.0052 \\
(0.0091)\end{array}$ & $\begin{array}{c}0.0062 \\
(0.0093)\end{array}$ & $\begin{array}{c}0.0057 \\
(0.0091)\end{array}$ \\
\hline Pop & $\begin{array}{c}0.1750^{* * * *} \\
(0.0242)\end{array}$ & $\begin{array}{c}0.1800^{* * * *} \\
(0.0237)\end{array}$ & $\begin{array}{c}0.1731^{* * *} \\
(0.0241)\end{array}$ & $\begin{array}{c}0.1785^{* * * *} \\
(0.0236)\end{array}$ \\
\hline Open & $\begin{array}{c}-0.0956^{\text {*** }} \\
(0.0217)\end{array}$ & $\begin{array}{c}-0.1123^{* * *} \\
(0.0217)\end{array}$ & $\begin{array}{c}-0.0962^{\text {*** }} \\
(0.0217)\end{array}$ & $\begin{array}{c}-0.1129^{* * * *} \\
(0.0216)\end{array}$ \\
\hline$G G D P$ & $\begin{array}{c}-0.1882^{* * *} \\
(0.0617)\end{array}$ & $\begin{array}{c}-1.2073^{* * *} \\
(0.2345)\end{array}$ & $\begin{array}{c}-0.1832^{* * * *} \\
(0.0616)\end{array}$ & $\begin{array}{c}-1.2128^{* * * *} \\
(0.2344)\end{array}$ \\
\hline GRev & $\begin{array}{c}-0.1017^{* * * *} \\
(0.0304)\end{array}$ & $\begin{array}{c}-0.1257^{* * * *} \\
(0.0303)\end{array}$ & $\begin{array}{c}-0.1047^{* * * *} \\
(0.0303)\end{array}$ & $\begin{array}{c}-0.1283^{* * *} \\
(0.0301)\end{array}$ \\
\hline GovSize & $\begin{array}{l}-0.0918 \\
(0.0857)\end{array}$ & $\begin{array}{l}-0.0720 \\
(0.0842)\end{array}$ & & \\
\hline Obs. & 527 & 527 & 527 & 527 \\
\hline
\end{tabular}

Source: Authors' Computation

Note: $* * * * *$, and $*$ denote the level of significance at $.1 \%, 1 \%$, and $5 \%$, respectively.

Table 6. Model Estimates with/without GovSize 
Appendix-III

Alternative model variants to Model (1)

\begin{tabular}{c|c|c|c|c}
\hline & $\begin{array}{c}\text { Excl. social factors } \\
(\text { HC, Pop })\end{array}$ & $\begin{array}{c}\text { Excl. macro-econ factors } \\
(\text { Open, GGDP })\end{array}$ & $\begin{array}{c}\text { Excl. fiscal factors } \\
(\text { GovSize, GRev })\end{array}$ & $\begin{array}{c}\text { All controls } \\
\text { excluded }\end{array}$ \\
\hline LR test stat & 56.0 & 25.8 & 13.0 & 106.3 \\
\hline$p$-value & 0.0000 & 0.0000 & 0.0015 & 0.0000 \\
\hline
\end{tabular}

Alternative model variants to Model (2)

\begin{tabular}{c|c|c|c|c}
\hline & $\begin{array}{c}\text { Excl. social factors } \\
(H C, P o p)\end{array}$ & $\begin{array}{c}\text { Excl. macro-econ factors } \\
(\text { Open, GGDP })\end{array}$ & $\begin{array}{c}\text { Excl. fiscal factors } \\
(\text { GovSize, GRev })\end{array}$ & All controls \\
& 60.8 & 43.0 & 18.6 & 117.4 \\
\hline LR test stat & 0.0000 & 0.0000 & 0.0001 & 0.0000 \\
\hline$p$-value & & & & \\
\hline
\end{tabular}

Source: Authors' Computation

Note: $\mathrm{H}_{0}$ : the alternative model is nested in the benchmark model.

Table 7. Likelihood Ratio Tests for Alternative Model Variants 